\title{
¿Teoría económica para el pasado o para el futuro?
}

\author{
Salvador Osvaldo Brand
}

\section{La obsolescencla de la teorla económica actual}

Hace casi 60 anos, 1936 para ser exactos, J.M. Keynes inspiró to que pomposamente se llamó la "revolución Keynesiana", dando a entender asi que el mundo anglo-sajón habia encontrado nuevas soluciones económicas mediamte una nueva teoría cuya base era una intervención modema del Estado en aquellas actividades factibles de proveer más empleo, a la vez que para reforzar los pilares carcomidos de la estructura económica capitalista.

Los economistas soviéticos - sin tener un baluarte individual como el Keynesiano- también hicieron grandes esfuerzos por brindar nuevos entoques basados en los aportes marxistas-leninistas sobre la socialización de los medios de producción para beneficio de las mayorias de una sociedad.

Hoy en 1993 podemos evaluar que durante el presente siglo, aún con esos estuerzos, la economia política como ciencia, para ser sinceros, no ha tenido mayor enriquecimiento.

$Y$ ahora es simple reconocer la causa de este hecho, que obedece fundamentalmente a que en todos los paises se repiten las mismas teorías obsoletas aprendidas con el dogmatismo que exigen los textos y que difunden en mala hora los protesores universitarios.

Trabajo de incorporación al Ateneo de El Salvador, julio de 1993. 
Aún entre nosotros, los economislas hispanoamericanos, grupo de donde han emergido teoricos muy destacados como Celso Furlado, Alonso Aguilar, José Consuegra, Raúl Prebisch, Maza Zavala, Oresle Popescu y otros grandes que han luchado por profundizar, mediante esquemas propios, la investigación continental de las verdaderas causas del subdesarrollo, aún con eso, decia, se ha avanzado poco por el arraigo de nuestra formación.

Pareciera ser que desde los tiempos de la economia política clásica europea, rusa y norteamericana, la economia ha progresado muy poco, y me refiero al aspecto cienlíitico, no al aspecto empírico de las políticas económicas.

Esto lambién ha sido resultado de que nuestra formación ha estado viviendo al pasado, creyendo que nuestro futuro sólo será una extensión del ayer, siguiendo una linea recta de nuestro presente.

Condicionados a pensar en línea recta, a los economistas nos resulta muy dificil imaginar alternativas al socialismo y al capitalismo. Nacidos y viendo en la penuria, como es la situación aclual, acoslumbrados a pensar en terminos de recursos limilados, apenas si podemos concebir una sociedad en la que el único objelivo es satisfacer las necesidades materiales básicas del hombre.

Pero el entomo continental y mundial es muy diterente del vigente hace 50 afios, que obliga a cambiar de pensamiento. En el último decenio del siglo, América Latina se enfremla a la doble tarea de recuperar el crecimiento económico y mejorar las condiciones de sus habilantes. Después de los anos trágicos de la década de los ochenla, caraclerizada por el estancamiento socioeconómico, los estuerzos de la región tendrán lugar en el marco de un orden global "Yracturado", donde coexisten procesos de globalización comercial, financiera, polílica, tecnológica, cultural y ambiental con prolundas y crecientes divisiones entre los paises y los grupos sociales que los consliluyen.

El escenario político internacional también está cambiando de manera verliginosa. Eslamos en Iransición hacia un mundo pos-bipolaz en el que las dilerencias entre Esle y Oeste ya no cuenlan como antes. Luego de siete decenios, el Iracaso del experimento económico y polílico de la Unión Soviética ha vuello irrelevante la lucha entre las superpolencias por difundir su modelo de organización social. La caida del muro de Berlín, la reunilicación alemana, las reformas democrálicas y la introducción de la economia de mercado en Europa Oriental, marcan el lin de la guerra fría y el inicio de una nueva era en la política internacional.

El Estado-nación ha perdido capacidad para controlar fenómenos y 
sucesos (financieros, comerciales, lecnologicos, ambientales) que trascienden fronteras. Además, cuando en un pais coexisten diversos grupos étnicos o religiosos, la preservación y alimación de sus propias idenlidades está generando presiones separatistas y disgregadoras. Sin embargo, cuesta aceptar que el Estado-nación eslé dejando de ser el punto focal para el ejercicio del poder y la toma de decisiones.

La economia mundial se ha translormado tan radicalmenle en tres decenios, que seria irreconocible para quien la viera desde la perspectiva de los anos cincuenta. La globalización de los mercados financieros ha creado una red de transacciones de todo tipo - movimientos masivos y rápidos de capital, especulación en mercado múltiples, inversiones en una apabullante variedad de instrumentos financieros- que han adquirido vida propia y se han desvinculado de la producción y dislribución de bienes y servicios.

Este conjunto de Iranstormaciones, cuya magnilud y simultaneidad no tiene antelación, hace que la siluación presente sea muy distinla de la de anos atrás. La concepción del mundo que liene la generación actual de políticos, prolesionales, gerentes, cientificos, dirigentes laborales y lideres comunitarios, se lorjo duranle los úllimos 25 anos y su acervo de conceplos, experiencias y valores parece cada vez más inadecuado e insuliciente para entender la cambianle realidad en el umbral de un nuevo siglo y actuar sobre ella con eficacia.

Mientras tanto, seguimos aterrados a la imagen que nos exhiben las economias desarrolladas y aspiramos a alcanzarlas como meta.

La realidad de los paises desarrollados, que en otro tiempo pareció tan poderosa, resulta ahora haber sido útil para ellos pero no para países como el nuestro.

Es más, desde finales de los años cuarenta, la estrategia dominante que ha gobernado los esfuerzos encaminados a reducir el abismo exislenle entre los ricos y pobres del mundo ha sido la industrialización.

Esta estrategia parte de la premisa de que las sociedades industria. les son la culminación del progreso evolutivo y que para resolver sus problemas, lodas las sociedades deben repetir la revolución induslrial, tal como se desarrollo en Occidenle, la URSS o el Japon. El progreso consiste en desplazar a millones de personas de la agricultura a la producción en serie. Requiere urbanización, infraestructura, bajar el crecimiento de la población, incrementar los servicios, elc. En resumen, la expectativa del desarrollo implica la imitación liel de un modelo que se ha creído elicaz. 
Aún entre nosotros, los economistas hispanoamericanos, grupo de donde han emergido teóricos muy destacados como Celso Furtado, Alonso Aguilar, José Consuegra, Raúl Prebisch, Maza Zavala, Oreste Popescu y otros grandes que han luchado por prolundizar, mediante esquemas propios, la investigación continental de las verdaderas causas del subdesarrollo, aún con eso, decia, se ha avanzado poco por el arraigo de nuestra formación.

Pareciera ser que desde los liempos de la economia política clásica europea, rusa y norleamericana, la economia ha progresado muy poco, y me refiero al aspecto científico, no al aspecto empírico de las políticas económicas.

Esto tambien ha sido resultado de que nuestra formación ha estado viviendo al pasado, creyendo que nuestro futuro sólo será una extensión del ayer, siguiendo una línea recla de nuestro presente.

Condicionados a pensar en línea recta, a los economislas nos resulta muy diticil imaginar atternativas al socialismo y al capitalismo. Nacidos y viendo en la penuria, como es la siluación actual, acostumbrados a pensar en terminos de recursos limitados, apenas si podemos concebir una sociedad en la que el único objelivo es satisfacer las necesidades materiales básicas del hombre.

Pero el entorno continental y mundial es muy dileremle del vigente hace 50 años, que obliga a cambiar de pensamiemo. En el último decenio del siglo, América Latina se enfrema a la doble tarea de recuperar el crecimiento económico y mejorar las condiciones de sus habilantes. Después de los anos trágicos de la década de los ochenla, caracterizada por el estancamiento socioeconómico, los estuerzos de la región tendrán lugar en el marco de un orden global "Iracturado", donde coexisten procesos de globalización comercial, financiera, polílica, tecnológica, cultural y ambiental con prolundas y crecientes divisiones entre los paises y los grupos sociales que los constituyen.

El escenario político internacional también está cambiando de manera vertiginosa. Estamos en Iransición hacia un mundo pos-bipolaz en el que las diferencias entre Este y Oeste ya no cuenlan como antes. Luego de siele decenios, el fracaso del experimenlo económico y político de la Unión Soviética ha vuello irrelevante la lucha entre las superpotencias por difundir su modelo de organización social. La caida del muro de Berlín, la reunificación alemana, las reformas democrálicas y la inlroducción de la economia de mercado en Europa Oriental, marcan el fin de la guerra tria y el inicio de una nueva era en la politica internacional.

El Estado-nación ha perdido capacidad para controlar fenómenos y 
sucesos (financieros, comerciales, tecnolbgicos, ambientales) que trascienden fronteras. Además, cuando en un país coexislen diversos grupos étnicos o religiosos, la preservación y afirmación de sus propias identidades está generando presiones separatistas y disgregadoras. Sin embargo, cuesta aceplar que el Eslado-nación esté dejando de ser el punto focal para el ejercicio del poder y la toma de decisiones.

La economia mundial se ha transformado tan radicalmenle en tres decenios, que sería irreconocible para quien la viera desde la perspecliva de los af́os cincuenta. La globalización de los mercados financieros ha creado una red de Iransacciones de todo lipo - movimientos masivos y rápidos de capital, especulación en mercado múltiples, inversiones en una apabullante variedad de instrumentos financieros- que han adquirido vida propia y se han desvinculado de la producción y distribución de bienes y servicios.

Este conjunto de transformaciones, cuya magnitud y simultaneidad no tiene antelación, hace que la siluación presente sea muy distinta de la de afios atrás. La concepción del mundo que liene la generación actual de políticos, profesionales, gerenles, cientificos, dirigentes laborales y líderes comunilarios, se forjó durante los últimos 25 anos y su acervo de conceptos, experiencias y valores parece cada vez más inadecuado e insuficiente para entender la cambiante realidad en el umbral de un nuevo siglo y actuar sobre ella con eficacia.

Mientras tanto, seguimos aterrados a la imagen que nos exhiben las economias desarrolladas y aspiramos a alcanzarlas como meta.

La realidad de los paises desarrollados, que en olro tiempo pareció tan poderosa, resulta ahora haber sido útil para ellos pero no para países como el nuestro.

Es más, desde finales de los ańos cuarenta, la estrategia dominante que ha gobernado los esfuerzos encaminados a reducir el abismo existente entre los ricos y pobres del mundo ha sido la industrialización.

Esta estrategia parte de la premisa de que las sociedades industriales son la culminación del progreso evolutivo y que para resolver sus problemas, lodas las sociedades deben repetir la revolución industrial, tal como se desarrolló en Occidenle, la UASS o el Japón. El progreso consiste en desplazar a millones de personas de la agricultura a la producción en serie. Requiere urbanización, infraestructura, bajar el crecimiento de la población, incrementar los servicios, elc. En resumen, la expectativa del desarrollo implica la imitación fiel de un modelo que se ha creido elicaz. 
Muchos gobiernos, incluidos los nuestros, han inlentado aplicar esa estrategia. Unos pocos como Corea del Sur o Taiwan, parecen estar consiguiendo crear una sociedad industrializada, pero la mayor parte de tales esfuerzos han concluido en frustración. En un país tras otro esta sucesión de fracasos se ha achacado a una desconcertante multiplicidad de razones: por el neocolonialismo, la mala planiticación, la cornupción, religiones retrógadas, tribalismo, crecimiento de la población, las transnacionales, la ClA, ir demasiado despacio, ir muy aprisa... en fin, cualesquiera que sean las razones, subsisle el hecho de que la búsqueda del progreso conlorme el modelo de la industrialización, ha naulragado muchas más veces que la que ha triunfado.

¿Es la industrialización clásica el único camino al progreso? ¿Tiene senlido imitar este modelo de la fase en que la propia civilización industrial se debate en sus agonias postreras?

Mientras las naciones desarrolladas se mantuvieron "triunfales" eslables y en progresivo enriquecimiento- lue tácil considerarlas como modelo para el resto del mundo. Pero a linales de la década del 60 había estallado ya la crisis del industrialismo.

A partir de ahi, huelgas, déficit liscales, quiebras, crimenes, drogas y turbación psicológica se extendieron por todo el mundo. Se desmoronaron escalas de valores y estrucluras. Se rompieron el sistema energético y la lamilia nuclear. La conlaminación, corrupción, inflación, alienación, racismo, burocratismo, consumismo desbocado, laceraron al sistema económico. Los economistas advirtieron sobre la posibilidad de un colapso tolal del sistema financiero.

Mientras tanto, un movimiento ecologista mundial advertía que la contaminación, la energía y la limitación de los recursos podrian imposibilitar a las naciones industriales a continuar sus operaciones normales. Además, aún en el supuesto de que la industrialización diera resullados milagrosos en las regiones pobres convertiria al planela en una gigantesca fábrica y ocasionaría una calásılrołe ecológica.

Ante las presiones de las demandas enlurecidas de los paises pobres al exigir una revisión total de la economia mundial y profundamente preocupadas por su propio fuluro, las naciones ricas empezaron a diseñar a mediados de la década del 70 una nueva estralegia para las zonas subdesarrolladas.

Casi de la noche a la manana muchos gobiernos, agencias de desarrollo, incluidos el Banco Mundial, la AID y el BID, cambiaron a to que puede llamarse una técnica para desarrollar la agricultura. 
Esta fórmula es casi una copia invertida de la estrategia de industrialización. En vez de estrujar a los campesinos y forzarlos a ir a las ciudades superpobladas, pone un nuevo acento en el desarrollo rural. En vez de esforzarse ciegamente por conseguir un PIB más allo, con la esperanza de que los benelicios acaben por llegar a los pobres, exige que los recursos sean canalizados directamente hacia "necesidades humanas básicas".

En vez de forrentar tecnologias ahorradoras de trabajo, el nuevo enfoque favorece la producción con mano de obra intensiva, con bajas exigencias de capilal, energías y especialización. En vez de construir acerias gigantescas o lábricas urbanas a gran escala, favorece instalaciones descentralizadas y a pequena escala disenadas para poblaciones lambién pequenas.

Volviendo al revés los argumentos de la industrialización, los delensores del desarrollo agricola pudieron demostrar que muchas tecnologlas industriales eran un desastre cuando se las Iransfería a un país pobre. Escaseaba la mano de obra especializada, por ello se abogó por una tecnología apropiada.

Hay mucho que decir en favor de esla nueva Iórmula. Atronta la necesidad de reducir la emigración masiva a las ciudades. Tiende lambién a hacer más habitables las aldeas, donde vive la mayor parte de la población paupérrima del mundo. Entaliza en el uso de recursos locales baratos en lugar de acudir a costosas importaciones. Sugiere una aproximación menos tecnocrática al desarrollo, tomando en consideración las costumbres locales y la cultura. Hace hincapié en mejorar las condiciones de los pobres, en vez de hacer pasar capital por las manos de los ricos con la esperanza de que se escurra algo.

Pero una vez reconocido todo eso, esta fórmula continúa siendo sólo eso... una estrategia para mejorar los peores aspectos de los países agrícolas, sin transformarlos. Es un remiendo, no un remedio y muchos gobiernos de lodo el mundo la perciben exactamente en esos lérminos.

Definitivamente ninguna teoria emanada del mundo de alta lecnologia, sea de lendencia capitalista o socialisla, va a resolver los problemas del mundo subdesarrollado, por to que debe surgir una nueva interpretación de nuestro atraso, libre de estas influencias que no sirven para superarlo.

Las estrategias de "desarrollo" del mañana ya no pueden esperarse que provengan de Washington, Moscú, París ni Ginebra, sino de Africa, Asia y América Lalina. Deberán ser nativas, adecuadas a las necesidades locales. No cargarán el acento en la economía a costa de la 
ecologla, la cultura, la religión o la esiructura lamiliar. No imitarán ningún modelo exterior.

Naturalmente, al lado de estas manifestaciones negativas de los anos recientes, se aprecian cambios cualitativos cuyo efecto es dificil de medir, pero que lienen un sesgo positivo. El primero se refiere al proceso de democralización polílica y a la mayor participación popular en toda la región hispanoamericana, que está sentando las bases de sociedades más abientas y pluralistas, capaces de adaptarse rápida y eficazmente a los cambios. Sin embargo, los recientes acontecimientos en Brasil, Haill, Perú, Venezuela y Guatemala indican que aún existen presiones en favor del autorilarismo político y que no está garantizada la permanencia de los regímenes democrálicos.

En segundo lugar, ha cambiado la perspectiva sobre la polílica eco. nómica, pues ahora se busca un equilibrio más razonable entre las fuerzas del mercado y la intervención estatal; se trata de eliminar distorsiones en los precios relativos y evitar sesgos contrarios a la exportación, disminuir las barreras al comercio internacional y afianzar la disciplina liscal, reformar el sislema Iribulario y definir prioridades para el gasto público.

Un tercer cambio cualitalivo en el decenio de los ochenta es la toma de conciencia sobre la necesidad de proleger el ambiente e incorporar el lactor ecológico en las estrategias de desarrollo. Aunque la preocupación es muy reciente, ya empieza a reemplazarse la negligencia y el descuido en la explotación de los recursos nalurales. La delorestación, la ubanización desmesurada, la contaminación ambiental, el deterioro de las condiciones sanilarias y la depredación de los recursos marinos han logrado movilizar a la opinión pública para ejercer presión política. Cada vez se dificulta más actuar impunemente contra el ambiente.

Por último, debe mencionarse que ha cambiado la calidad del liderazgo en todos los niveles: desde organizadores vecinales, comunares y laborales, hasta ministros, ejecutivos de empresa y jeles de Estado. En algunos casos, una nueva generación ha reemplazado a los políticos. empresarios y sindicalistas tradicionales; en otros, la misma generación de líderes ha renovado sus ideas y actitudes.

Pero aún con todos eslos resultados no se ha creado una nueva estrategia de desarrollo ni las tecnologías aplicadas han favorecido uniformemente a los paises pobres. Mientras algunos han registrado éxilos espectaculares, olros han mostrado pocos progresos, pues éslo depende de variables lales como la posición geográfica del pais, su relación geopolítica con los países centrales, su infraestructura industrial y el 
nivel de entrenamiento de su fuerza de trabajo.

Irónicamente, a medida que más y más paises en el mundo luchan por industrializarse, la industrialización está perdiendo el papel clave que una vez tuvo como indicador definitivo del desarrollo nacional.

O sea que ya es tiempo de que pensemos diferente. Si continuamos creyendo que la sociedad del manana será simplemente una versión ampliada del presente, no necesitamos hacer gran cosa para prepararnos para ello. Pero no es suliciente decir que los cambios a que nos entrentaremos serán revolucionarios, porque anles de poder controlarlos se necesita una nueva forma de identificarlos y analizarlos, tal es el caso de la decadencia de la industrialización.

\section{La decadencla de la industrlalización}

El industrialismo fue un borbotón en la historia, un mero lapso de tres siglos perdidos en la inmensidad del liempo. Cualquier búsqueda de la causa de la revolución indusirial eslá condenada al fracaso. La tecnologla por sí sola, no es la fuerza impulsora de la historia. Ni bo son por sí mismos los valores o las ideas. Ni lo es la lucha de clases. La economia sola tampoco puede explicar éste ni ningún otro acontecimiento histórico.

De lodas las fuerza que influyeron para formar la civilización industrial, pocas tuvieron consecuencias apreciables más claramente que la brecha abierta entre productor y consumidor y el desarrollo de una red de intercambio que ahora se llama "mercado". Esa invisible cuna produjo todo el sistema monetario modemo con sus bancos centrales, las bolsas de valores, su ética contractual, el comercio mundial y los planificadores burocráticos. De este divorcio entre productor y consumidor surgieron muchas de las presiones hacia la uniformización, la especialización, la sincronización y la centralización.

Al extenderse la producción tabril, el elevado costo de la maquinaria y la estrecha interdependencia del trabajo exigian una sincronización muy refinada. Si un grupo de trabajadores de una sección se demoraba en la terminación de una tarea, otros situados más adelante de la cadena de producción se retrasarán también. Asi, la puntualidad, nunca tan importanle en las comunidades agricolas, se convirtió en una necesidad social. Y empezaron a proliferar los relojes de pared y de bolsillo.

No fue una coincidencia el que en las culluras industriales se ensehara a los ninos desde temprana edad a tener conciencia del tiempo. Se condicionó a los alumnos a llegar a la escuela cuando sonaba la campana, a fin de que más tarde pudiera conliarse en que llegarian a la fábrica 
- a la oficina cuando sonase la sirena. En todas las sociedades del industrialismo también la vida social quedó supeditada al reloj y adaptada a las exigencias de la máquina.

Los nifios empezaban y terminaban el ano escolar en épocas uniformes. Los hospitales despertaban simultáneamente a lodos sus pacientes para el desayuno. Los sistemas de transporte se apretaban en las horas pico. Las actividades comerciales tenian sus horas y temporadas estacionales sincronizadas con las de sus proveedores y distribuidores. Las rutinas más Intimas de la vida quedaron sincronizadas en el ritmo induslrial. En Estados Unidos y la URSS, en Singapur y Suecia, en Francia y en Dinamarca, Alemania y Japón, las familias se levantaban simultáneamente, comian a las mismas horas, salian al Irabajo, trabajaban, regresaban a casa, se acoslaban, dormian e incluso hacian el amor más o menos al unisono, al paso que la civilización entera aplicaba el principio de la sincronización.

La civilización del industrialismo no se limitó a allerar la naluraleza y la cultura; alleró lambién la personalidad, ayudando a producir un carácter social nuevo, pues sustiluyó el canio del gallo por el silbato de la fábrica; el chirrido de los grillos por el rechinar de las llanlas, iluminó la noche, ampliando las horas de vigilia. Trajo imágenes visuales que ningún ojo habia visto hasla entonces: la lierra folografiada desde el cielo, - monlajes surrealistas en la sala de cine local, o formas biológicas reveladas por polenles microscopios. El aroma de la tierra durante la noche dejó paso al olor a gasolina y al hedor de fenoles. Los sabores de la carne y las verduras se alteraron artilicialmente. Todo el paisaje perceptual se trańsformó.

También se halla presente un lado más oscuro. Si bien la industrialización mejoró mucho las condiciones de vida, también provocó violentas consecuencias, sobre todo el irreparable daño causado a la trágil bióstera de la tierra. Debido a su tendencia conlra la naluraleza, a su población en conslante aumento, a su tecnología feroz y a su incesante necesidad de expansión, provocó una mayor catásırofe ambiental que ninguna Era precedente.

Hasla ahora ninguna civilización habia creado los medios para destruir no una ciudad, sino al planeta enlero. Jamás los océanos se enIrentaron a la toxificación; especies enteras desaparecieron de la Tierra como resultado de la avaricia humana; jamás las minas llenaron tan salvajemente de cicatrices la superficie de la tierra; jamás los aerosoles mermaron la capa de ozono, ni la termopolución amenazó el clima del Planeta.

Similar, pero aún más compleja, ha sido la influencia del colonialis- 
mo. El sometimiento a esclavitud de los indios para trabajar en la minas suramericanas, la introducción del sistema de plantaciones en grandes áreas de Asia y Africa, la exlorsión deliberada de las economias dominantes para acomodarlas a la necesidad y voracidad de las naciones industriales, todo ello dejo una estela de sufrimienlos, hambre, enfermedad, desculturización y racismo, cuyas heridas aún no sanan.

La revolución industrial creó un sistema social maravillosamente integrado, con sus propias instituciones sociales y sus propios canales de inlormación, todos ensamblados entre si. Pero a otro nivel creó una forma de vida llena de distensión económica, conflicto social y malestar psicológico.

$Y$ todo esto se desarrollo en torno a la que ahora conocemos como "el mercado".

Hasla la revolución industrial, la gran mayoría de lodos los alimentos, bienes y servicios eran consumidos por sus propios produclores, sus familias o una pequeña élite, que recogía los excedenles para su propio uso. Existía el comercio, desde luego. Un pequefio número de intrépidos mercaderes transporlaban mercancias a lo largo de miles de kilómetros por medio de camellos, carretas o barcos. Sin embargo, todo este comercio representaba proporciones mínimas comparado con la producción para el uso inmediato por el esclavo o siervo agrícola.

El industrialismo modificó violentamente estas situación. En lugar de personas y comunidades esencialmente autosulicienles, creó el mercado, y por tanto una civilización en la que casi nadie es autosuficiente y donde casi todos los bienes y servicios se destinan a la venta o intercambio.

A partir del surgimiento del mercado, la sociedad fue absorbida en el sistema del dinero. Los valores comerciales se convirtieron en predominantes y el desarrollo económico se transformó en el objelivo fundamental de los gobiernos, fuesen capilalistas o socialistas.

La industrialización dio nacimiento a los primeros mercados verdaderamente nacionales y al concepto mismo de economia nacional. Junto con ello llegó el desarrollo de instrumentos para la dirección económica tales como la planificación central en las naciones socialistas, y los bancos centrales y políticas monelarias y fiscales en los países capitalislas, instrumentos que en la actualidad, se están revelando ineficaces, para desconcierto de economistas y políticos que tratan de dirigir el sistema. Surgieron también poderosos consorcios transnacionales que dominan no sólo los mercados internos, sino también los exteriores.

La nueva economía global se ve así, dominada por las grandes cor- 
poraciones transnacionales. Eslá mantenida por una ramificada induslria bancaria y financiera que opera a velocidades electrónicas. Engendra dinero y crédilo que ninguna nación puede regular. Avanza hacia monedas transnacionales, no a una moneda "mundial" sino a una variedad de monedas, cada una de ellas basada en una "canasta" de divisas nacionales. Esla economía está averiada por la deuda externa de los paises no desarrollados de una magnilud inimaginable. Es una economía mixta, con empresas capitalistas y empresas estalales realizando operaciones conjuntas y trabajando codo a codo. Y su ideologla no es "laissez faire" ni marxismo, sino globalismo, mostrando asl que el nacionalismo ha quedado anticuado.

El globalismo se presenla como algo más que una ideología servidora de los inlereses de un grupo limitado. Exactamente del mismo modo que el nacionalismo prelendia hablar en nombre de la nación entera, el globalismo pretende hablar en nombre del mundo entero y surge en el preciso momento histórico en que muchos países pobres luchan desesperadamente por establecer una idenlidad nacional, porque la nacionalidad era necesaria en el pasado para lograr la industrialización. Pensando más allá del industrialismo, los palses ricos, contrariamente, están reduciendo, desplazando o anulando el papel de la nación.

El problema es que ante estos avances, nuestras esinucturas políticas están hoy más delerioradas aún más de lo que to estaban en la década de los setenta. Si esto es asl, debemos presumir que los gobiernos serán menos compelentes y menos sagaces que antes, al enfrenlarse a las crisis venideras de los años novenla.

$Y$ si lo único por lo que tuviéramos que preocuparnos fuese por elegir al "mejor" dirigente, los problemas podrian resolverse dentro del entramado del actual sistema político. Pero en realidad, el problema es mucho más profundo. En esencia, los dirigentes -incluso los mejoresresultan inválidos porque se han quedado anticuadas las instiluciones a cuyo través deben actuar.

Vale la pena comentar la decadencia de los sistemas políticos vigenles. En primer lugar, nuestras estructuras políticas y gubernamentales fueron disehadas en una época en que la nación-Estado eslaba naciendo lodavía y cada gobierno podía lomar decisiones más o menos independientes. Hoy ésto ya no es posible, aunque conservernos el mito de la soberanla.

También nuestras instituciones políticas reflejan una anticuada organización ejeculiva. El gobierno liene ministerios, direcciones y departamentos consagrados a campos concrelos lales como la economía, la 
agricultura, los asuntos exteriores, la defensa, el comercio, el correo, el transporte. La Asamblea Legislaliva tiene, similarmente, comisiones deslinadas a eslos campos. Pero ni el gobiemo más auloritario ha podido resolver el problema de interrelación, o sea cómo integrar las actividades de todas estas unidades para que puedan producir programas coherenles, en lugar de una confusa mezcolanza de efectos contradictorios y mutuamente anuladores.

Los gobiernos y las instituciones parlamentarias de la era industrial fueron disefiados para tomar decisiones con un ritmo sosegado, adecuado a un mundo en el que un mensaje podía tardar una semana de San Salvador a La Unión. Hoy si un terrorisla toma rehenes en el Libano, funcionarios de Washington, Moscú, Paris o Londres pueden verse obligados a responder con decisiones en cuestión de minutos.

Las comunicaciones instantáneas han dilatado el tiempo de tal manera que una gestión presidencial de cinco años de duración en la actualidad, se enfrenta a más acontecimientos, más dificultades y conflictos, que cualquier otra en un período de 5 años en el pasado.

La aceleración del cambio ha rebasado la capacidad decisoria de nuestras instituciones, tornando anticuadas las estructuras políticas actuales, con independencia de toda ideologia de partido.

Los sislemas políticos vigentes esıán copiados de modelos inventados antes de la aparición del sistema fabril, o sea antes de la retrigeración, de la luz de energía hidraúlica, de la máquina de escribir, anles de la invención del teléfono, anles que volara Wilbur Wright, antes que el automóvil y el avión cortaran distancias, antes que la radio y la televisión empezaran a forjar su alquimia en nuestras menles, antes de los proyectiles nucleares, antes de las computadoras, las folocopiadoras, las píldoras anticonceptivas, los transistores y el rayo láser. Fueron creados en un mundo intelectual y cientifico casi inimaginable.

A medida que vamos siendo sacudidos por una crisis tras olra, sentiremos más la necesidad de resolver los problemas prescindiendo no sólo de nuestros anticuados artilugios. Al entrar en la era del fuluro, aunque queramos ampliar la libertad humana no podremos hacerlo con sólo defender las instituciones existentes. Debemos inventar otras, tal como hicieron hace dos siglos los lundadores de América.

Leyes $e$ instituciones deben ir de la mano con el progreso de la mente humana. A medida que haya nuevos descubrimienlos, surjan nuevas verdades y argumentos, las instiluciones deben avanzar y mantener el ritmo de los tiempos.

Tal como dice Alvin Toffler en su obra "La Tercera Ola", unas genera- 
ciones nacen para crear, otras para mantener una civilización. Las generaciones que desencadenaron el industrialismo como ola de cambio histórico se vieron obligadas, por la fuerza de las circunstancias, a ser creadoras. Los Montesquieu, Mill, Madison, Juárez y Bolivar inventaron la mayor parte de las formas políticas que todavía aceplamos como naturales.

Por eso debiéramos estar apresurados para entrentar la necesidad de crear esas nuevas formas. El problema es que en ninguna parte está la obsolescencia más avanzada que en nuesira vida política, y en correspondencia, es en este terreno donde se encuentra menos ingenio, menos capacidad y menos disposición a considerar un cambio fundamental. Los políticos raramente ven más allá de las próximas elecciones.

Para avanzar debemos desencadenar el más amplio debate público, a través de conferencias televisadas, discusiones, convenciones, para generar el más amplio despegue de propuestas ingeniosas dirigidas a la reestructuración política.

Si empezamos ahora con nuestros hijos, podemos tomar parte en la reconstrucción, no sólo de nuesıras anticuadas estructuras políticas, sino también de la civilización misma.

Al usar cualquier elemento que se elija para evaluar el presente que se va desvaneciendo, es vilal comprender que el juego industrial ha terminado, su impulso se ha disipado y su fuerza va menguando a medida que empieza una nueva "ola", metáfora que emplea A. Toffler para simbolizar la decadencia del industrialismo y el nacimienlo de una nueva civilización, la cual se visualiza a través de los cambios que estamos viviendo. Cambios que no son independientes entre sí, que no son fruto del azar. La quiebra de la lamilia nuclear, por ejemplo, la crisis mundial de la energía, la caída del socialismo, la prolileración de cultos o religiones y de la televisión por cable, el incremento del horario laboral flexible y la aparición de movimientos separatistas, no son acontecimientos aislados, son parte de un fenómeno mucho más amplio: la muerte del indusırialismo y presentan la imagen de la nueva civilización que está haciendo irrupción entre nosotros.

Es tan profundamente revolucionaria esła nueva civilización, que constituye un reto a todo lo que hasta ahora ha sido aceptado sin mayor discusión. Las viejas formas de pensar, las viejas fórmulas, dogmas e ideologías, por útiles que hayan sido en el pasado, no se adecúan ya a los hechos. El mundo que está emergiendo rápidamenle del choque de nuevos valores y tecnologias, nuevas relaciones geo-politicas, nuevos 
estilos de vida y formas de comunicación, exige ideas, categorias y conceptos completamente nuevos. No podemos encerrar el mundo embrionario de manana en los cubículos convencionales del ayer.

Dos cambios hacen que ya no sea posible la continuación "normal" de la Era Industrial. En primer lugar, hemos llegado a un punto de inflexión en la guerra conlra la naluraleza. La biósfera, simplemente, no tolerará por más tiempo el ataque industrial. En segundo lugar, no puede seguirse confiando en energia no renovable y barata, principal subvención hasla ahora del desarrollo industrial.

Estos hechos, claro, no significan el fin de la sociedad tecnológica ni el fin de la energía. Pero si significan que lodo avance tecnológico luturo se verá condicionado por nuevas limilaciones ambienlales. Indican también que hasta que encuentren nuevas fuentes, las naciones industriales sufrirán violentos síntomas de retracción, mientras la lucha por descubrir nuevas formas de energía acelerará por sí sola la Iransformación política y social.

Simultáneamenle eslá desapareciendo esa olra subvención oculta que son las materias primas baralas, como produclo del fin del colonialismo.

El costo creciente sin cesar de los combustibles actúa en contra de los intereses de la industrialización. O sea, el hecho de que los procesos de producción necesilan grandes aportes de energia para producir aumentos relativamente pequeńos de nueva energia "neta", actúa contra el sistema. En fin, aunque los reactores nucleares, la gasificación del carbón, las plantas de licuefacción y otras lecnologias semejantes puedan parecer fuluristas, en realidad son trutos de un pasado de una era de la industrialización atrapada en sus propias y tatales contradicciones.

El objelivo debiera ser cambiar a un sislema más "metabólico" que elimine el despilfarro y la contaminación asegurando que el producto y el subproducto de cada industria se convierla en materia prima par la siguiente. Tal sistema no sólo será más eficiente, sino que, además, reducirá al mínimo lodo daño a la bióstera.

El cambio hacia una nueva Era apunta hacia una mayor diversidad, no hacia mayor unitormización de la vida. Y eslo implica a ideas, convicciones políticas, proclividades sexuales métodos educativos, concepciones religiosas, actiludes étnicas, gustos musicales, modas y formas familiares.

Los cambios son globales y afectan a numerosos paises. $Y$ son revolucionarios no en sentido político, sino en el sentido de que implican una translormación de granıamplitud. 
La nueva industria va desde la electrónica, el láser, la óptica, las comunicaciones y la intormática, hasta la genética, la energía alternativa, la ciencia oceánica y espacial, la ingeniería ecológica y la agricultura de ecosistemas, todo ello reflejando el saldo cualitativo en el conocimienio humano que en la actualidad se traslada a la economía de cada dia.

Las anliguas herramienlas de la política económica nacional, al igual que los impuestos o las regulaciones bancarias centrales para el flujo monetario, junto con la planificación central, son instrumentos burdos concebidos para una economía orientada hacia la producción masiva de bienes. Y fueron previslas para una economia de base nacional, no para un esquema en que las economías transnacionales o regionales han alcanzado más peso que la economia inlerna.

Por eso es que los términos "derecha" e "izquierda" son reliquias del auge industrial que ahora ha pasado a la historia. "Derecha" e "izquierda" lienen que ver con la forma como se dividieron la riqueza y el poder dentro del sistema industrial, pero hoy en dia la lucha entre los mismos es algo parecido a una rifna sobre el vaivén de un barco que se hunde.

La sociedad se está apartando de la era industrial lan rápidamenle, que nuestras Iradicionales etiquetas políticas se han convertido en algo pasado de moda y equivoco, al igual que las calegorías económicas.

Ya la crisis no es del sistema capitalista, como lo predijo Marx, pues el mundo está inmerso en una crisis ideológica. Después de examinar las nociones capilalistas de libre mercado o al manxismo tal como to hemos conocido, o al liberalismo y al estatismo de asistencia social o las teorias tradicionales del desarrollo del llamado Tercer Mundo, todos eslos planteamientos parecen cada vez menos relevantes a medida que los acontecimienlos hacen lambalear las formulaciones leóricas vigenles. Esta ruptura ideológica es necesario aceptarla, en preparación para la emergencia de otras ideologías del fuluro con mayor alcance y consistencia.

El capitalismo y el socialismo, tal como los conocemos, contienen cada uno falales contradicciones. La oleada de cambios eslá convirtiéndolos a ambos en anlicuados, pues son dos produclos de la revolución industrial.

Nuestros hijos y nielos, lal vez algún dia verán a la gran contienda mundial entre el capitalismo y socialismo con cierto aire divertido y condescendiente, asi como ahora se consideran las balallas que tuvieron lugar entre güelfos y gibelinos, que durante los siglos XIII y XIX asolaron Italia, pero en el siglo XV, ya habian sido olvidadas. A duras penas 
puede alguien recordar sobre la causa de esas guerras. En forma semejante, la tensión entre el capitalismo y el socialismo es producto de la era industrial. Como esta va acabando, también se desvanece esa división de los sistemas.

\section{La esperanza en el futuro}

\section{A. Una nueva oportunidad para el movimlento Imiegracionlate}

¿Qué papel pueden jugar nuestros paises en este nuevo proceso postindustrial? La historia de Hispanoamérica está llena de suefios, uloplas, grandes propositos y enormes descalabros. Los anhelo de unidad y de progreso conjunto han tropezado con infinidad de obstáculos, a veces los mismos, que han sido concebidos a la par de los propositos.

En 1823 Simón Bolívar en su calidad de Libertador Presidemte de Colombia tirmó con el gobierno provisional de México un Tratado de Unión, Liga y Confederación Perpetua que básicamenle pretendia erigir una alianza defensiva contra cualquier amenaza interna o externa a la independencia recién conquistada.

El 7 de diciembre de 1824 Bolívar convoco desde Lima a las naciones apenas liberadas del dominio español a una reunión conlinental. Dos anos después se celebró en Panamá el Congreso de Anfictionía, que según el Libertador constituiria el primer paso para instaurar un mecanismo de defensa de la inlegridad y soberanía de los paises hispanoamericanos amenazados por las potencias europeas y el expansionismo estadounidense, ya entonces sustentado en la ideologla de la Doctrina Monroe. Bolivar denunció antes que ningún otro gobernante de América, la presencia expansionista y hegemónica del coloso del norte al proclamar: "Los Estados Unidos parecen deslinados por la providencia para plagar la América de miserias a nombre de la libertad".

La Antictionia Americana arrojó resullados pobrísimos aunque en $\mathrm{Pa}$ namá se firmó el Tratado de Unión, Liga y Confederación Perpetua. Cabe sefialar que el Tratado debia confirmarse en Tacubaya, México, en un plazo de 8 meses, pero éste nunca se llevó a cabo. Los subsecuentes intentos del Libertador para cristalizar la aspiración de una América unida lambién fracasaron. El deseo de Bolivar de conservar en la independencia la cohesión que Hispanoamérica habia tenido en la colonia no lue posible. En lugar de una gran república americana y de una unidad que hubiera podido tavorecer un tránsito temprano a la modernización y el desarrollo, el continente se fragmenló aún más y se hizo presa de un nuevo coloniaje, como lo anticipara Bolivar. 
Los afanes de unidad han formado parte esencial del pensamiento de gigantes como San Martín, Juárez y José Martl, quienes con su legado han mantenido vivo hasta hoy el ideal bolivariano. Hispanoamerica sufre en la actualidad una severa crisis idenlificada con el estancamiento, la inflación y el sobreendeudamiento que han profundizado la pobreza en loda la región; la concentración de la riqueza y la desigualdad social se muestran con grosera evidencia; el desempleo abierto se ha acrecentado y la economía sublerránea y el mercado informal $\rightarrow$ reducto del subempleo- aglulina a amplios estratos de la población del área. La violencia y el delerioro social consecuenle de la crisis, también han propiciado el florecimiento de actividades ilícitas. Los efectos distorsionadores de los narcodólares son nolables en Bolivia, Perú y Colombia y últimamente en Centroamérica.

La profundidad de la crisis derribó viejos paradigmas desarrollistas y dio paso a la búsqueda de nuevos caminos para salir de la frustración. Ello condujo a la revilalización de los anhelos de la unidad regional, inspirada en la necesidad de sobrevivir en un mundo pleno de cambios, donde poderosos bloques económicos, comerciales y financieros, eslán configurando el mapa económico y político inlernacional de la nueva centuria. Los dirigentes latinoamericanos saben que esas transformaciones sólo podrán encararse mediante la acción conjunta.

Es en este marco donde se inscriben los recientes acuerdos y negociaciones bilaterales y subregionales emprendidos en el continente en los últimos años. Ahi se encuadra el encuentro de Guadalajara en julio de 1991, donde se congregaron 23 jefes de Eslado americanos, para buscar nuevos caminos de cooperación efectiva y conducir a las naciones a una participación más activa en la nueva conlormación internacional.

El llamado proceso de globalización de la economia mundial implica consideraciones económicas y comerciales y de aspectos vinculados a la geogratía polílica del orbe. Así, la globalización ha llevado consigo el replanteamienlo no sólo del conceplo de fronteras, sino también de la identidad nacional y la soberanía.

Como se comentó, la experiencia lalinoamericana en maleria de inlegración no es reciente. Empero, los resultados de esos inlentos se han quedado muy rezagados con respecto a los propósilos que animaron el esluerzo conjunto. A tines de los setenta los modelos de integración en la región mostraron una tendencia hacia el estancamiento y la declinación del intercambio, comportamiento que se profundizó en el descenio de los ochenla. 
En términos generales las causas de ese comportamiento, que crearon un sentimiento de frustración y escepticismo se atanen tanto a factores económicos como políticos. Con respecto a estos últimos, se considera que la ausencia de un entomo democrático y la inestabilidad politica y social de los últimos 30 anos obstruyeron la firma de convenios duraderos, provocando la ausencia de proyectos políticos de apoyo a la integración y cooperación, y jusliticaron frecuentes modificaciones de las eslralegias económicas que lejos de erigir una política común, agravaron los desacuerdos y dieron paso a la desintegración comercial. Las discrepancias políticas y los diterendos territoriales de algunos paises lambién molivaron que el esluerzo común fracasara.

En el ámbilo económico, las dificultades de los procesos de integración se derivaron de la falta de voluntad política para armonizar las politicas económicas; de la débil estructura induslrial, la similitud y escasa diversificación de sus bienes exportables; del excesivo proteccionismo que hacia ineficaz cualquier acuerdo que implicara un inlercambio fluido; de la sujeción de los precios de sus productos a faclores exógenos con la consecuente vulnerabilidad de sus sectores externos, y de la falla de financiamienlo y mecanismos de aplicación.

Los países lalinoamericanos saben que de no emprender polílicas económicas orientadas a retomar el camino del crecimiento con equidad, se dirigirán al sigo XXI sin haberse liberado del atraso y la miseria. Afortunadamente los gobernantes centroamericanos son conscientes de su siluación y han mostrado gran inlerés en revitalizar el movimiento inlegracionista. Los avances que logre cada uno de nuestros países, la tortaleza y congruencia macroeconómica de sus estralegias de apertura económica y la viabilidad real de la alianza con las naciones poderosas, determinarán el lugar y las tareas de nuestras economías en el mercado multipolar de la nueva cenluria.

No más utopias, no más suefios. Con sus imperiosas y anejas necesidades en el fuluro postinduslrial, Cenlroamérica no puede ya esperar que las buenas inlenciones derroten a la hisloria. En los úllimos anos la miseria y la insalubridad han alcanzado a miles de seres humanos en nuestra región. El contenido de los acuerdos y el sentido de las negociaciones para establecer convenios, no deben perder de vista que de lo que se Irata es de obtener benelicios hacia un desarrollo que se extienda a lodos los rincones de la región.

La hisloria ensefía con crudeza, que la voluntad polilica no basta, sino que es preciso convertirla en poder político real. Esa es la decisión histórica que está pendiente de lomar por nuestros gobernantes. 


\section{B. Perspectlvas polítlcas y economlcas}

En los dos últimos anos, el mundo se ha transformado aceleradamente, provocando cambios en casi todas las alianzas políticas; asl, la unión de las dos Alemanias, el surgimiemto del Mercado Común Norleamericano, la ruptura del Pacto de Varsovia, y sobre todo el sorprendente viraje de la Unión Soviética, identifican que la línea actual predominante es el cambio no obstante, aún no se contigura la cara de la nueva siluación mundial.

Actualmente todas las fuerzas políticas y sociales despliegan esfuerzos dirigidos a conseguir posiciones ventajosas en la disputa por consolidar nuevas zonas económicas y políticas. Los pactos y bloques anleriores están cediendo terreno a otros espacios de concerlación; por eso estadounidenses y soviéticos están ahora más cerca que antes.

Las naciones del Tercer Mundo también están evolucionando y se reacomodan a las nuevas ondas por medio de inicialivas propias o con el respaldo de programas de ajuste eslruclural. El respaldo internacional para los movimientos democráticos ha sido lormidable, aunque todavia subsistan los problemas económicos y sociales que tradicionalmenle han sulrido los países subdesarrollados.

¿Qué hacer en un pais pobre como es El Salvador, mientras se consuma la decadencia de un sistema denlro del cual nunca pudimos alcanzar beneficios para las grandes mayorias?

Al aceplar el surgimiemo de un nuevo sistema de vida, debe reflexionarse que sus benelicios no los va a gozar la generación actual, aunque sí los disfruten a lo mejor desde nuestros nielos en adelante.

Pero en esta lase de post-guerra deben proponerse acciones concretas para enfrenlarnos en el plazo inmediato y en el mediano plazo a las deficiencias exislentes en el pais.

El diagnóstico neoliberal elaborado en términos tecnocrálicos afirma que una de las causas inmediatas de la crisis de paises como el nuestro, se encuentra en la crisis internacional de los anos ochenta combinada con la caida de los precios de las exportaciones y de alzas agudas en las tasas de interés que provocó déficits cuantiosos en las cuentas externas y aumenlos en la deuda externa. El delerioro se manifesió en la fuga de capitales, el elevado desempleo y subempleo, broles inflacionarios y sobre todo en la mala distribución del ingreso.

En esle ámbito se sostiene que la clave del ajuste con crecimienlo radica en encontrar el manejo equilibrado de los instrumentos de política monetaria, crediticia, cambiaría y fiscal que para un nivel dado de finan- 
ciamiento externo, logren cumplir con los objetivos de estabilización y apoyen los cambios estructurales con menos costos en lérminos de crecimiento en el corto plazo.

Pero, naturalmente, el enloque neoliberal no es el único factible de aplicar. Otras corrientes como la neoestructuralista afirman que los problemas económicos principales y la condición de subdesarrollo de nuestros paises no se deben tanto a distorsiones inducidas por la política económica, sino que predominan las de carácter histórico y de indole endógeno y estructural.

Este entoque utiliza como muestra palpable de esta realidad tres características que identifican a economias como la nuestra: a) la vigencia de una dependencia externa que dada la organización del comercio y el sistema financiero internacional, conduce a una especialización empobrecedora; b) el predominio de un aparato produclivo incapaz de absorber eficientemente el aumento de la fuerza de trabajo, y c) la persislencia de una distribución del ingreso muy concentrada, que evidencia la incapacidad del sistema para reducir la pobreza.

Cualquiera que sea el fundamento teórico del diagnóstico, debe $\infty$ ncluirse en que en el corto plazo la estrategia a emplear en El Salvador para enfrentar nuestros problemas no debe ser doctrinaria sino enminentermente realista.

En forma concrela, la dirigencia económica del pais debería hacer esluerzos por lo menos en cuatro áreas para manlener estabilidad y crecimiento: a) disciplina liscal; b) administración más eliciente de las empresas públicas; c) expansión de las exportaciones, y d) evilar distorsión de precios.

Muchos de nuestros problemas como son el déficil en la balanza de pagos, inflación, dislorsión de precios, conlroles administralivos $\theta$ insuficiente inversión, tienen su origen en un desbalance fiscal. La restauración de la disciplina fiscal es una condición necesaria para el crecimiento. En vista de que se mantiene la inflación, la estabilización monetaria puede ser una precondición para recobrar las rentas públicas y por to tanto para la reconstrucción de las finanzas estalales; pero la estabilización monetaria no será posible sostenerla a menos que se restaure la disciplina fiscal.

La producción de infraestructura y de bienes y servicios por parte de las empresas públicas represenla una atta proporción de la producción nacional y su administración y finanzas tienen grandes electos en las finanzas públicas y crédito en general. Lamentablemente, con frecuencia su adminisıración ha mostrado debilidades debido a manejo político o 
insuliciente aulonomia operacional y en consecuencia su situación financiera es débil, pueslo que su administración fue empleada como vehículo para consumo o subsidiación, como fuente de empleo o medio de corrupción.

La expansión de las exportaciones en manulacturas actualmente lideriza el enfoque universal. Las economias de escala proveen mayor magnitud de mercado de venta, mayores posibilidades de expansión de la producción, a coslos menores, aumentando asl la ocupación, ingreso y márgenes de beneficio. Más aún, el aumento en las ganancias de las exportaciones ayudará a aliviar las restricciones externas en el crecimienlo, tema crítico en la mayoría de los paises en desarrollo.

Actualmente se insiste mucho en la mejora de los precios de los productos agrícolas. Las necesidades de proveer incenlivos de precios más atractivos es notoria, lo cual serviria para aumentar la producción nacional, especialmente la de los alimentos.

Un objetivo irrenunciable dentro de estas acciones de política economica es la consecución de equidad y justicia social en un marco de profundización democrática. Aún con la influencia de la crisis, el mayor énfasis ha de ponerse en los problemas de la extrema pobreza y en las medidas para aliviarla, sin perjuicio de que con el crecimiento oblenido hasla 1993, puedan introducirse cambios fundamentales en el mediano y largo plazo en maleria de equidad, asociados con la superación de la helerogenidad de la estructura productiva.

La crisis actual brinda una oportunidad para probar nuestras capacidades y a la vez para confirmar si efectivamente comprendemos con claridad sus causas y consecuencias. Por la crisis también es pertinente que modifiquemos nuestros pensamientos y criterios, pues la necesidad del reajuste político-económico no reconoce ideologlas ni fanatismos. Reconoce realidades y se mide por resultados. Por eso nuestra participación en este proceso es impostergable.

Las organizaciones de izquierda jugarán un papel preponderante en el fuluro de El Salvador, pues anle los profundos cambios de Europa del Esle y la Unión Soviélica, puede esperarse que si al menos una parte de la izquierda se adapta a la nueva situación, dichos cambios son capaces de producir un efeclo muy favorable para muchos anos.

En la práctica, tanto la izquierda como la derecha de hoy -si es que cabe esta clasificación-, deben actuar dentro del marco de la realioad salvadorefia. La idea misma de la revolución en que durante decenas de anos se concentró la izquierda radical, ha perdido sentido. Además de eso, después de las elecciones de 1990 en Nicaragua vemos que la 
revolución puede ser reversible y no sólo mediante la fuerza como ocurrió en Guatemala en 1954, Brasil en 1964, Chile en 1973 y Granada en 1983, sino que puede ser trenada de manera pacílica, con el consentimiento o el apoyo de aquellos para quienes este proceso fue destinado originalmente, según la experiencia rusa y nicaragüense.

Para los partidos de izquierda y de centroizquierda, asi como para el electorado y la inleleclualidad, el colapso del mundo socialisia dista de ser una caláslrofe o experiencia deprimente; debe tomarse en la misma forma que para los paises del Este, donde significo un resultado deseable y no un retroceso.

La izquierda podría ser capaz de triunfar y recibir su chance en el gobierno o desenmascararse a si misma como incompetente y obsoleta. Más, será juzgada, por lo menos, según sus propios mérilos y no tras el prisma de la sombra anticomunista y antisoviética, como se le juzgó Iradicionalmente.

Este lenómeno facililará la concertación entre lodas las luerzas políticas para lograr un consenso en aceptar que las dislorsiones estruclurales de El Salvador consliluyen la raiz principal de los problemas económicos y, que en gran medida, explican la permanencia de la condición de subdesarrollo en que vivimos, sin perjuicio de reconocer también que de ahi se han derivado fallas y errores de política económica.

Seamos optimistas. Saquémosle provecho a la dura experiencia vivida estos úllimos 15 años y que nos sirvan de eslimulo para todos aquellos que pensamos y seguiremos pensando como Simón Bolivar, Benito Juárez y José Martí, que la América Latina sólo tiene un camino: su propio camino.

Muchas Gracias 